\title{
Género y valores sexuales. Un estudio de caso entre un grupo de mujeres mexicanas
}

\author{
Ivonne Szasz
}

En este artículo se presenta un análisis de las declaraciones de un pequeño grupo de mujeres residentes en un contexto mural del centro de México sobre su vida sexual y el inicio de la procreación, con el objetivo de plantear algunas reflexiones e interrogantes sobre posibles relaciones entre la dimensión de género, el comportamiento sexual, la anticoncepción y el inicio temprano de la reproducción.

El análisis se refiere a las valoraciones expresadas sobre su primera relación sexual, la posibilidad de tener relaciones sexuales no procreativas, su autonomia para tomar decisiones sobre anticoncepción, la posibilidad de sentir deseos y placer, sexual y la posibilidad de evitar relaciones sexuales no deseadas. Se proponen algunas reflexiones sobre posibles relaciones entre las normas culturales sobre la construcción del género y los valores sobre la sexualidad que pueden estar afectando el comportamiento sexual y anticonceptivo de algunas mujeres mexicanas. La posibilidad de explorar estas relaciones en forma sistemática en investigaciones sobre el tema puede contribuir al conocimiento de los condicionantes socioculturales de la anticoncepción y la fecundidad temprana en México.

\section{Introducción}

En años recientes, los estudios sociodemográficos han iniciado investigaciones sobre la sexualidad como parte de la búsqueda de las relaciones entre la cultura, la an ticoncepción y la fecundidad, así como para ubicar la salud reproductiva en un marco de derechos humanos que incluyen el bienestar sexual y reproductivo, o para comprender el contexto social de la epidemia del virus de inmunodeficiencia humana (Bozon y Leridon, 1993; Dixon-Müeller, 1993).

En relación con el descenso de la fecundidad en México, han llamado la atención los pocos cambios que ha experimentado este fenómeno en tre las mujeres jóvenes y el bajo uso de anticonceptivos entre las mujeres sexualmente activas que no han tenido hijos, así como la incidencia del aborto clandestino y la relación positiva entre inicio temprano de la procreación y paridad elevada (Poder Fjecutivo Federal, 1995).

En este artículo analizo las declaraciones de un pequeño grupo de mujeres residentes en un contexto rural respecto de su vida sexual y el inicio de la procreación, con el objetivo de plantear algunas reflexiones e interrogantes sobre posibles relaciones entre la dimensión 
de género, el comportamiento sexual, la anticoncepción y el inicio temprano de la reproducción.

En la primera parte propongo algunas ideas sobre el contexto social heterogéneo cambiante en el que ocurren los comportamientos sexuales de las mujeres ên el México actual. En la segunda sección, analizo las valoraciones expresadas por trece mujeres del municipio de Actopan, en Hidalgo, sobre su primera relación sexual, la posibilidad de tener relaciones sexuales no procreativas, su autonomía para tomar decisiones sobre anticoncepción, la posibilidad de sentir deseos y placer sexual y la posibilidad de evitar relaciones sexuales no deseadas. En las consideraciones finales, propongo algunas reflexiones sobre las posibles relaciones entre las normas cutulturales sobre la construcción del género y los valores sobre la sexualidad que pueden estar afectando el comportamiento sexual y anticonceptivo de algunas mujeres mexicanas. La posibilidad de explorar estas relaciones en forma sistemática en investigaciones sobre el tema puede contribuir al conocimiento de los condicionantes socioculturales de la anticonicepción y la fecundidad temprana en México.

Este artículo corresponde a una versión revisada de la ponencia denominada "Género y valores sexuales en mujeres mexicanas" que presenté en el Coloquio Internacional Los Nuevos Paradigmas de la Sexualidad que se llevó a cabo en la ciudad de México los días 30 y 31 de enero y 1 de febrero de 1995.

El contexto social de lạ reproducción y la sexualidad en el México contemporáneo

En las sociedades occidentales los valores sobre la sexualidad se han transformado conjuntamente con diversos cambios históricos. Jeffrey Weeks propone que el mundo occidental cambió en los últimos dos siglos desde un sistema valorativo que ligaba el género, la sexualidad y la procreación al ordén divino, hacia la visión de un orden natural aprehensible mediante el conocimiento científico. En los últimos años, ha cambiado además hacia la incertidumbre sobre las posibilidades de la ciencia para el control de la naturaleza, característica del periodo posmoderno, y hacia una creciente globalización y diversificación de las ideas, generándose una crisis de valores en torno de la sexualidad (Weeks, 1995):

En México, además de esos cambios de paradigmas, se han producido otras transformaciones sociales. La vida de las mujeres mexi- 
canas ha cambiado más en los últimos veinte años que la vida de läs mujeres europeas en el último siglo. Entre los cambios más sobresalientes se cuentan la rápida transformación de una sociedad rural en una urbana; el drástico cambio en la escolaridad de la población; el intenso y rápido cambio en los patrones reproductivos; los cambios productivos, en la participación económica de la población y en la estructura de clases de la sociedad; los cambios consecuentes en la familia y las redes sociales; cambios en las concepciones sobre el amor y la vida en pareja; y la creciente incertidumbre sobre los atributos de cada género vinculada con los cambios materiales.

En la sociedad mexicana de los últimos veinte años coexisten estructuras productivas, formas de organización familiar, patrones reproductivos y visiones del mundo diversas y de signo contradictorio. Ninguna de esas visiones tiene, además, contornos nítidos, pues se permean entre sí y están sujetas a una acelerada transformación.

El cambio de una sociedad rural a un país eminentemente urbano es muy reciente. En la primera mitad del siglo, la mayor parte de los mexicanos vivía en el medio rural y se vinculaba con la agricultura familiar. Actualmente, más de dos tercios de los mexicanos viven en centros urbanos, y los que permanecen en el medio rural están permeados por las formas de vida, visiones y valores urbanos mediante la televisión, los transportes, la escuela, los servicios médicos y las redes migratorias, que han dado lugar a una urbanización del contexto rural.

Los cambios en la escolaridad aparecen estrechamente vinculados con cambios en los patrones reproductivos. A principios del siglo, la población mexicana era analfabeta y hace apenas treinta años la mayor parte tenía muy baja escolaridad. Actualmente, la mayor parte de las generaciones más jóvenes alcanza la primaria completa, y una proporción importante tiene estudios secundarios. Este paso del mundo rural iletrado a un contexto urbano, asalariado y escolarizado, ha significado, además de los cambios materiales, cambios simbólicos, que afectan la construcción de identidades y la visión del mundo. Separan de manera drástica las concepciones, las opciones de trabajo y el comportamiento reproductivo de las mujeres más jóvenes respecto de las generaciones mayores (García y Oliveira, 1994).

Uno de los cambios más rápidos y más intensos, ocurrido en un lapso de veinte años, es el referente a los niveles de fecundidad. A principios de los años setenta las mujeres mexicanas tenían en promedio alrededor de siete hijos. Apenas veinte años después, ese promedio se 
redujo a menos de la mitad. También en menos de veinte años, la mayoría de las mujeres mexicanas dejó de tener a sus hijos en casa con el apoyo de mujeres de su comunidad, y pasó a tener atención médica en sus embarazos y partos. Una proporción importante dejó de amamantar a sus hijos, alimentándolos con leche artificial. La reproducción cambió en pocos años desde el ámbito femenino y comunitario al médico-hospitalario (Zavala, 1988; Mellado, Zoila y Castañeda, 1989; Salas, 1995).

Las transformaciones económicas que dieron lugar al proceso de urbanización cambiaron la estructura productiva del país y la composición de la población económicamente activa. Entre las décadas de 1940 y 1970 se produjo una transferencia de la fuerza de trabajo desde el sector primario hacia los sectores secundario y terciario de la economía, y desde el trabajo por cuenta propia en pequeñas unidades familiares al trabajo asalariado urbano, cambiando la estructura de clases de la sociedad (García, 1988).

La participación económica de las mujeres experimentó cambios particulares. Mientras la población permaneció mayoritariamente en las zonas rurales, las mujeres participaban en la economía como ayudantes familiares no remuneradas, en algunas faenas reservadas a las mujeres en las haciendas, preparando alimentos y prendas de vestir, y por medio de la venta ambulante en mercados locales y regionales. Las grandes migraciones rural-urbanas iniciadas en los años treinta fueron protagonizadas principalmente por mujeres jóvenes, quienes se insertaron en el mercado de trabajo urbano, concentrándose en el servicio doméstico. Cerca de la mitad de las mexicanas actuales en edades reproductivas participa en la actividad económica, principalmente en las ciudades, en su gran mayoría dedicándose al comercio, los servicios sociales y comunitarios, los servicios personales y la industria del vestido (Arias, 1991; Oliveira, 1984; Szasz, 1995).

Otros cambios menos estudiados se refieren a las transformaciones en la familia, en las redes sociales y en las visiones sobre el amor y las reglas para el cortejo y la formación de parejas (Tuirán, 1993; Rocha, 1995; Salles, 1995). En los centros urbanos los lazos de familia extensa y de identidad comunitaria se han hecho más débiles, transformando los vínculos de obligaciones mutuas, solidaridad grupal y control social. El concepto del amor romántico centrado en la pareja y los atributos de atractivo sexual para la elección del cónyuge ha permeado masivamente mediante los medios de comunicación. El acceso creciente de las mujeres a la instrucción secundaria ofrece a las jó- 
venes la oportunidad de conocer varones de su edad e interactuar con ellos fuera del ámbito del control familiar y comunitario, y el grupo de pares pasó a ser determinante en las percepciones sobre el cuerpo, el amor, el comportamiento sexual y la formación de pareja.

Estas rápidas transformaciones materiales y culturales han producido tensiones y cambios en algunos de los deberes y conductas esperados para cada género. Entre las jóvenes rurales, el control social de la sexualidad limitaba su contacto con varones fuera del ámbito familiar desde la aparición de la menarquia. Actualmente, una proporción importante de jovencitas puede optar por la escolaridad en lugar del embarazo y la unión temprana, y puede interactuar con jóvenes en la escuela secundaria, generándose cambios en la percepción del deber ser femenino. Otro cambio se refiere al deber masculino de unirse con la:joven a quien embarazaba si era señorita al iniciarse la relación sexual (Amuchástegui, 1994). La mayor movilidad extrahogareña de las jóvenes aumenta también su incertidumbre sobre el posible abandono del varón después de iniciada una relación sexual. Estos cambios han acarreado una disminución de los embarazos y uniones en edades jóvenes, pero también un aumento de las jóvenes madres sin pareja (Villaseñor y Alfaro, 1995). Han significado cambios e incertidumbre sobre los atributos de cada género.

Los cambios materiales, en especial los referidos a la crisis económica, la apertura al comercio internacional, el debilitamiento del Estado-bienestar y el aumento de la escolaridad y la participación económica de las mujeres de los sectores populares, han generado tensiones entre la actividad económica, el cuidado de los hijos y la movilidad extrahogareña de las mujeres, modificando las relaciones de pareja y cambiando las percepciones sobre el deber ser femenino (García y Oliveira, 1994; Mummert, 1986; Rosado, 1990). A su vez, el descenso en la fecundidad y la atención hospitalaria del parto se han dado con una creciente influencia de los servicios médicos en las decisiones reproductivas de las mujeres y una penetración del discurso oficial sobre las ventajas económicas de limitar la procreación a dos hijos. Este discurso entra en contradicción con las normas religiosas y de género que reducen la sexualidad y el cuerpo de la mujer a la procreación y señalan a la maternidad como única fuente de valoración de lo femenino, sin que los planteamientos de limitación de la fecundidad ofrezcan fuentes alternativas de valoración de la feminidad (Figueroa, 1995).

A su vez, estos cambios han puesto en tensión el deber ser masculino. Las crisis económicas han acarreado dificultades para que los 
varones cumplan con su rol proveedor, originando cambios en la conyugalidad y en las relaciones entre los géneros. Desde el inicio del proceso de asalariamiento masivo de la mano de obra mexicana, los bajos salarios y la necesidad de los traslados temporales de los varones impulsaron la actividad económica femenina, pero ésta se desarrollaba dentro del hogar (Arias, 1991; Mummert, 1986; Rosado, 1990). El proceso de urbanización, y posteriormente la crisis de los años ochenta y la reducción de los salarios masculinos, aumentaron la participación económica femenina fuera del hogar, en especial en actividades por cuenta propia. En los sectores populares, estas actividades femeninas generaron conflictos y tensiones en el interior de los hogares, no solamente por el control de la sexualidad femenina, sino también porque cuestio. naron el rol proveedor del varón (Corona, 1989; Katzman, 1993). La incertidumbre de losjóvenes varones sobre su capacidad de cumplir con las normas de género ejerciendo su papel de proveedores ha cambiado sus ideas y comportamiento sobre la sexualidad, la procreación y la formación de pareja (Liendro, 1993; Villaseñor y Alfaro, 1995).

Estos intensos cambios sociales ocurridos en un periodo tan breve permiten caracterizar a la sociedad mexicana como un contexto de rápido cambio. En México coexisten las visiones que sitúan las construcciones del género, la sexualidad y la procreación en el orden divino con la imagen médico-científica del cuerpo, la sexualidad y la reproducción, con la incertidumbre posmoderna y con las imágenes de la televisión. En el país conviven el mundo rural y el urbano, los grupos étnicos, el mestizaje y los sectores occidentalizados, los campesinos, los trabajadores por cuenta propia, los asalariados y las personas involucradas en los procesos más recientes de flexibilización laboral. Dentro de cada grupo, y hasta en cada persona, conviven los valores de la Iglesia católica medieval, el discurso científico-racionaltecnocrático, los medios masivos de comunicación y los mensajes de la economía global. Es un contexto de hibridación económica, social y cultural en que se mezclan formas de organización productiva y de inserción laboral, visiones del mundo y formas de organización familiar y comunitaria diversas y de signo contradictorio.

Se trata de una sociedad en rápido cambio, en que las visiones sobre la sexualidad no se pueden vincular únicamente con dimensiones valorativas, sino con profundos cambios materiales e institucionales, y pueden estar afectadas por la incertidumbre sobre las condiciones de subsistencia, que a su vez inciden sobre las relaciones de pareja, la vida familiar y la sexualidad, sin que cambien las raíces más profundas 
de la construcción cultural del género, edificadas en un México campesino, colonial y religioso, de relaciones socialesijerárquicas más rígidas que las actuales. La sexualidad actual en México comprende significados diversos, y el estudio de los valores sexuales requiere dar cuenta de esa extrema complejidad.

Sin embargo, la investigación sobre las relaciones entre la construcción social y las identidades de género, por una parte, y el comportamiento sexual de grupos específicos de la población mexicana, es muy incipiente y no ha analizado las posibles relaciones entre las normas y valores relativos al género y el comportamiento hacia la anticoncepción. En el siguiente apartado se presentan algunas reflexiones basadas en un pequeño estudio de caso en el medio rural, que situadas en el contexto de cambio social antes reseñado apuntan hacia posibles líneas de investigación en este campo.

Valores sexuales en un grupo de mujeres rurales del municipio de Actopan, Hidalgo

Las reflexiones que se presentan en este trabajo se basan en una investigación sobre los procesos de toma de decisiones entre un grupo de mujeres rurales que usan la anticoncepción quirúrgica (Figueroa, 1994). La investigación combinó un acercamiento estadístico descriptivo de las características de los procesos de toma de decisión anticonceptiva de las mujeres operadas del país en 1987, con un acercamiento cualitativo a las historias de vida y los procesos de apropiación de su cuerpo y sus decisiones reproductivas en trece mujeres rurales que optaron por la anticoncepción quirúrgica.

Las reflexiones que aquí se presentan corresponden a la parte cualitativa del estudio, y no constituyen evidencias sino únicamente una síntesis de lo expresado por ese pequeño grupo de mujeres, e hipótesis interpretativas sobre posibles relaciones entre sus valores en torno de la sexualidad y sus comportamientos anticonceptivos y reproductivos. Estas relaciones posibles se proponen para ser exploradas de manera sistemática en futuras investigaciones.

En los meses de abril y mayo de 1994 entrevistamos a una pequeña muestra de las mujeres operadas en los tres años anteriores en el municipio de Actopan, Hidalgo. En la muestra se trató de incluir diferentes tipos de mujeres según su edad, paridad y escolaridad, aunque no fueran estadísticamente representativas de un conjunto mayor. 
Las características de las mujeres entrevistadas expresan la situación de cambio social referida en el apartado anterior: aunque residen en un contexto rural tradicional, cerca de la mitad de ellas accedió a la educación secundaria, algunas fueron socializadas en la ciudad de México debido a migraciones de sus padres, y la mayor parte ha tenido atención médica en sus embarazos y partos. La distribución de algunas de estas características entre las mujeres entrevistadas se presenta en el apéndice 1 .

Las mujeres entrevistadas optaron por la anticoncepción quirúrgica a diferentes edades, pero en todos los casos después de haber tenido al menos dos hijos dentro de una unión conyugal. Las decisiones sobre la anticoncepción fueron analizadas en otro documento, pero coinciden con diferentes apreciaciones que se hacen en este artículo sobre la apropiación del cuerpo y la sexualidad: algunas delegan la capacidad de decisión en su esposo y el médico; otras han tomado decisiones an ticonceptivas al margen de la opinión de sus esposos y siguiendo las sugerencias de los servicios de salud; otras -las más escolarizadas, las másjóvenes- deciden conjuntamente con el esposo y de acuerdo con los criterios de los servicios de salud, incluyendo casos de desinformación, presiones e imposición del método; por último, existen casos de mujeres que parecen decidir de acuerdo con sus propios deseos, enfrentándose con distintos tipos de presiones familiares e institucionales (Figueroa, 1994).

En los apartados siguientes se señalan los valores que expresaron las mujeres entrevistadas en torno a su capacidad de sentir deseos y placer sexual, a su primera relación sexual, y a sus opiniones sobre la sexualidad procreativa y no procreativa, la posibilidad de negarse a relaciones sexuales no deseadas y su autonomía para tomar decisiones anticonceptivas. Estas valoraciones se relacionan con las percepciones sobre opciones alternativas a la maternidad y el matrimonio para las mujeres.

Valoración de la capacidad de sentir deseos y placer sexual, y de la posibilidad de evitar relaciones no deseadas

Casi todas las mujeres entrevistadas iniciaron sus relaciones coitales antes del matrimonio. Sin embargo, la mayor parte manifestó que no deseaba esas relaciones. Algunas, las que iniciaron esas relaciones a los 14 o 15 años, "se dejaron llevar" sin tener muy claro lo que esta- 
ban haciendo. Otras, algo mayores, se sintieron obligadas porque habían aceptado ir a vivir a casa de los padres del novio. Otras consintieron en las relaciones porque el novio las deseaba. Una vez iniciadas tales relaciones, se sentían obligadas a continuarlas.

Después de haber tenido hijos dentro de una unión conyugal, las mujeres entrevistadas valoraron muy positivamente el uso de anticonceptivos. Pero no relacionaban la anticoncepción con la posibilidad de liberar su sexualidad de la procreación, sino con eliminar el sufrimiento de los embarazos y partos, y evitar tener más hijos. Las relaciones sexuales, aun usando anticonceptivos, ocurrían en la mayor parte de los casos únicamente porque las demandaba el esposo. La posibilidad de experimentar sensaciones corporales y erotismo en las relaciones conyugales no fue aceptada por la mayor parte de las entrevistadas. Apareció como un valor positivo únicamente en algunas de las mujeres más escolarizadas. La mayor parte se refirió a su propio cuerpo como carente de la posibilidad de experimentar sensualidad, al mismo tiempo que disponible para que el hombre sienta placer.

Para casi todas las entrevistadas parece importante poder evitar las relaciones sexuales cuando no las desean. Algunas, menos escolarizadas y de mayor edad, ni siquiera conciben la posibilidad de dialogar con el esposo al respecto: "para eso se casa una", "ni modo que les diga uno que no". Otras, viven con conflicto la posibilidad de expresar cuando no desean una relación sexual, sea porque el esposo reacciona enajado o sea porque ellas sienten culpa de decirlo: "no se les puede decir siempre que no", "qué va a pensar", "los hombres buscan eso", "luego dice que si tengo otro". Unas pocas expresan que pueden decirle a su cónyuge, a veces, que no desean tener relaciones, y que eso no les genera conflictos en la pareja. Sin embargo, aun estas mujeres no expresan su deseo de evitar las relaciones todas las veces que quisieran, porque sienten que serían demasiadas.

La posibilidad de demandar relaciones sexuales cuando las desean fue valorada positivamente por las dos mujeres más asertivas y autónomas del grupo entrevistado. Otras, que manifiestan haber experimentado deseos y placer en sus relaciones maritales, señalan que no se atreverían a pedir tener relaciones solamente porque ellas las desean. No solamente no se atreverían, sino que afirman que esa situación casi no se presenta, porque sus esposos siempre son sexualmente más demandantes que ellas. Finalmente, el grupo mayoritario de mujeres que afirman no desear las relaciones conyugales y no disfrutarlas, ni siquiera pudo imaginar la posibilidad de solicitarlas. En general, se 
quejaron de la frecuencia de las relaciones sexuales, señalando que posiblemente las disfrutarían si no fueran "tan" frecuentes. Algunas señalaron como limitantes para una vida sexual placentera la presencia de niños o de otros parientes en el mismo cuarto.

\section{Valoración de su primera relación sexual}

Todas las mujeres entrevistadas expresaron alguna forma de valoración negativa de su primera relación sexual, a pesar de que ninguna refirió situaciones de violencia o falta de consentimiento. Expresaron sentimientos de pérdida de valor personal, de entrega de algo valioso. Este sentimiento de pérdida únicamente se vio compensado en los casos en que la mujer recibió algo a cambio del valor entregado o perdido: una unión conyugal posterior, un hijo.

A pesar de la relativa voluntariedad del inicio de su vida sexual, casi todas las mujeres expresaron haber experimentado una pérdida de su valor personal al tener su primer coito. Algunas de sus expresiones fueron:

“...pues mal, o sea sí me sentí mal...”.

“...bueno, a la vez yo me quise ir, pero a la vez digo, qué tal si me abandona por acá y yo cómo me regreso... y yo ya había... yo ya había cometido el error con él, sí".

“...ya las metí todas... cuando una se engaña qué quiere usted... pus mete uno la pata".

“...pus había perdido... ser mujer...”.

“...pues... tonta la entrega... después de eso me sentí mal, me arrepentí en seguida, me sentí sucia...”.

“...uno ya perdió con él todo, ya no eres lo mismo que cuando uno estaba señorita, ya ni modo ya...".

“...llegué señorita con él y me trató mal... yo para mí al lado de él valía yo menos...".

“...yo había sido señorita y yo me había entregado a él...".

"...no es la misma de antes... o sea, cuando es uno señorita...".

“...me sentía yo menos por haber hecho eso...".

“...me había arruinado yo misma...”.

A su vez, las entrevistadas expresaron sentimientos de adquisición de valor personal al iniciar una unión conyugal, con su primera pareja sexual o más adelante, con otra pareja. 
La frecuencia con que estas mujeres relatan haber iniciado sus relaciones sexuales antes del matrimonio parece indicar que éste es un patrón común de inicio de la sexualidad femenina en este contexto. Sin embargo, esta pauta de conducta somete a las mujeres a un sentimiento de pérdida de valor, que solamente se recupera con el inicio de la vida conyugal. Las expresiones de las mujeres entrevistadas parecen indicar que, mientras las relaciones sexuales forman parte de un proceso que culmina con la unión conyugal, valorada positivamente, el deseo de las mujeres de tener esas relaciones es valorado negativamente. En particular, rechazan el deseo de una sexualidad no orientada a la conyugalidad o la procreación.

Estos sentimientos aparecen reforzados por el relato de sanciones sociales vinculadas con la sexualidad prematrimonial: temen que tener relaciones les va a cambiar el cuerpo y se va a saber que ya no son señoritas; temen que por utilizar anticonceptivos antes de haber tenido hijos queden estériles; piensan que si el hombre propone el uso de anticonceptivos es porque las quiere "nomás para un rato", "nomás para relaciones"; temen que si le dicen al hombre que no quieren embarazarse de inmediato "se puede enojar" o "las puede dejar".

\section{Valoración de la sexualidad procreativa}

En la investigación social sobre la mujer mexicana se suele afirmar que en México existe una elevada valoración de la maternidad ( $\mathrm{Fi}$ gueroa, 1995; Elu y Leñero, 1992). La elevada fecundidad prevaleciente hasta comienzos de los años setenta se atribuía, precisamente, a la valoración única del género femenino por medio de la maternidad. Investigaciones recientes han señalado que aun en las mujeres que trabajan fuera del hogar, la motivación principal para desempenar una actividad remunerada son los hijos (García y Oliveira, 1994).

Nuestros resultados apuntan hacia una elevada valoración de la conyugalidad y de la maternidad dentro de la unión. Las mujeres entrevistadas en el municipio de Actopan expresaron sentimientos positivos hacia la maternidad únicamente cuando ésta ocurría dentro de una unión conyugal. La sexualidad procreativa era valorada positivamente si terminaba en una unión conyugal, pero las mujeres que se embarazaron al iniciar su vida sexual y no se casaron expresaron sentimientos muy negativos hacia su embarazo. Los embarazos que no fueron seguidos por una unión fueron referidos como "fracasos", el 
abandono fue considerado indicativo de que el novio "nada más la quería para relaciones". Las mujeres se sintieron "arruinadas", "mal", y casi todas intentaron maniobras abortivas tales como ingerir tés, hacer ejercicios bruscos o propinarse golpes. Una de ellas afirmó que quería "destriparse y sacarse lo que tenía dentro".

Todas las mujeres entrevistadas que se embarazaron antes de una unión, aun las que después se casaron, expresan la primera percepción de su embarazo como un momento de incertidumbre y temor. El miedo se refería, en todos los casos, a la inseguridad sobre la reacción del varón. El miedo solamente fue superado en los casos en que el hombre respondió uniéndose con la mujer, pero aun así, dos de ellas que se embarazaron a los catorce años y se casaron sintieron que habían arruinado su vida por el hecho de haberse embarazado tan temprano.

Los sentimientos negativos vinculados al embarazo sin pareja se refieren a un cuestionamiento de la vida sexual previa de la mujer. En el contexto estudiado, existe una norma social que indica que el varón que tiene relaciones sexuales con una mujer "señorita" tiene la obligación de casarse con ella, especialmente si la embaraza. Esta obligación no existe si lajoven no era señorita. De manera que quedar embarazada y no casarse cuestiona la virginidad previa de la mujer. El embarazo no permite que la mujer se reponga de la pérdida de valor personal que representa el inicio de las relaciones sexuales; solamente la unión conyugal le permite recuperar ese valor. La única circunstancia en que la joven no pierde su valor a pesar de embarazarse sin un esposo es la violación. Si la joven fue forzada a la relación sexual, su familia y su comunidad la apoyarán, aunque quede embarazada.

Los sentimientos expresados por estas mujeres indican que en el contexto estudiado lo que se valora negativamente son las manifestaciones de deseo sexual en las jovencitas. Las jóvenes pueden tener relaciones sexuales cuando son hijas de familia, pero el objetivo de esas relaciones no parece ser la expresión de afecto o el placer propio, ni siquiera la búsqueda de un hijo, sino la búsqueda de un embarazo que dé origen a una unión conyugal. Tener relaciones sexuales sin embarazarse, o embarazarse sin casarse, aparecen como expresiones de deseo sexual femenino o de experiencia sexual previa de la:joven, y son valoradas negativamente. En cambio, las relaciones sexuales forzadas, por ser manifiestamente no deseadas, no acarrean sanción para lajoven.

De las expresiones de estas mujeres se desprende que la sexualidad procreativa no siempre es valorada positivamente. Esto ocurre so- 
lamente cuando la procreación ocurre dentro de una unión conyugal. Lo que se valora es la maternidad en la conyugalidad, no la maternidad por sí sola, aunque lo que da origen a la unión suele ser un embarazo. El deseo de hijos no aparece en el discurso de estas mujeres como una motivación para buscar la unión. El gusto por los hijos aparece muy condicionado a la opinión del varón. Si el novio o esposo expresó alegría al saber del embarazo, o si antes del embarazo manifestó su deseo de tener hijos, la mujer declara sentimientos de alegría frente al embarazo o al alumbramiento. A su vez, el abandono del varón fue seguido, en todos los casos, por sentimientos de tristeza de la mujer por estar embarazada. Una sola de las mujeres entrevistadas manifestó haber deseado a sus hijos por sí mismos.

El sentimiento de preferencia por los hijos varones no fue unánime. Frente al primer embarazo, algunas mujeres expresaron que deseaban un hijo varón, otras que su esposo deseaba un hombrecito, pero la mayor parte deseaba "lo que viniera" y algunas preferían una niña. Las mujeres que fueron madres solteras fueron coincidentes en preferir un niño, y todas las que señalaron ventajas de tener un hijo hombre refirieron las desventajas de las mujeres a dos tipos de sufrimientos: aquéllos derivados de la vida reproductiva -embarazos, dolores de parto, efectos secundarios de la anticoncepción, pérdidas, hemorragias, hospitalizaciones-y el peligro de ser una mujer sola, abandonada por un hombre.

\section{Valoración de la sexualidad no procreativa}

Diversas expresiones de las mujeres entrevistadas sugieren que las relaciones sexuales que no tienen como objetivo directo la procreación son valoradas muy negativamente en el contexto estudiado.

Salvo dos excepciones, todas las mujeres que entrevistamos refirieron un lapso muy breve entre la primera relación sexual y su primer embarazo. Algunas señalaron incluso que se embarazaron la primera o segunda vez que tuvieron relaciones sexuales. Independientemente de que asi haya ocurrido en la práctica, estas afirmaciones indican que las mujeres de este contexto pueden tener vida sexual antes de casarse, pero no pueden admitir que esas relaciones no fueran procreativas. El embarazo rápido parece indicar que no hubo deseo erótico por parte de la joven, y que su intención no era sentir placer. Casi todas niegan haber buscado o propiciado estas relaciones. Únicamente 
dos de ellas manifiestan una intencionalidad diferente de complacer al novio o ceder a sus presiones: la que deseaba un hijo para ella, y la mujer más escolarizada, quien buscaba ser importante para elijoven, dejar en él "un recuerdo imborrable". A su vez, como ya se refirió, todas las mujeres expresaron haber perdido valor con motivo de sus primeras relaciones sexuales.

Aun dentro de la unión conyugal, las relaciones sexuales previas al primer embarazo son reportadas como una pérdida de la mujer, pocas veces son indicadas como placenteras, y tratar de posponer el primer embarazo tuvo una connotación negativa en los pocos casos en que se intentó: temores de abandono del esposo o miedo a quedar estéril.

El rechazo de la procreación también fue valorado negativamente. La mayor parte de las mujeres ni siquiera entendió cuando se le pidió que opinaran sobre mujeres que nunca desearan tener hijos en su vida. La posibilidad pareció inconcebible en el contexto estudiado. El calificativo que recibían esas mujeres era de "locas". A la vez, todas rechazaron valorativamente, de manera muy tajante, la posibilidad del aborto, calificándolo de crimen. Sin embargo, varias refirieron maniobras abortivas al ser abandonadas con un embarazo, o frente a embarazos no deseados después de varios hijos, haciendo una separación valorativa tajante entre "maniobras para que baje la regla" y un legrado.

La única posibilidad de vida sexual femenina no procreativa aceptada en el contexto estudiado es la que se produce dentro de la unión conyugal y después de haber tenido al menos dos hijos, o haber completado la descendencia deseada. Esta permisividad se expresa en el uso de anticonceptivos. Las mujeres entrevistadas valoran negativamente la anticoncepción antes del matrimonio, y aun dentro del matrimonio si no han tenido hijos. Incluso, después de haber tenido hijos sin unirse, y aun en el caso de que sea más de un hijo, el uso de anticonceptivos es valorado negativamente. Únicamente se aceptan cuando se han tenido hijos - más de uno- dentro de una unión conyugal. Sin embargo, la mayor parte de las mujeres entrevistadas se refiere a una vida sexual sin deseo, sin placer y sin demandas propias. Incluso, las pocas mujeres que expresaron haber disfrutado de las relaciones sexuales con su esposo, declararon una disminución del deseo erótico y de la capacidad orgásmica después de haberse operado.

Estas expresiones nos permiten concluir que, en el contexto estudiado, la sexualidad no procreativa se acepta únicamente en mujeres 
casadas y madres, pero no se acepta como posibilidad de deseos y de placer femenino. Separar las relaciones sexuales de la procreación se hace por los hijos, para mantenerlos mejor, o para disminuir los sufrimientos y riesgos derivados de la reproducción, pero no por deseo, placer o erotismo. Estos últimos rasgos parecen propios de lo masculino, y por tanto son inaceptables en las mujeres.

\section{Valoración de opciones alternativas a la maternidad y el matrimonio para las mujeres}

La posibilidad de optar por aceptar el deseo erótico o el placer sexual, e incluso la posibilidad de decidir sobre tener o no relaciones sexuales, cuándo tenerlas, cómo tenerlas y con quién, requieren ciertas condiciones sociales previas para poder ser ejercidas.

La elección entre diversas opciones sexuales, la posibilidad de optar, requiere la posibilidad de existencia social de diversos estilos de vida. En el caso de las mujeres mexicanas de la zona rural estudiada, nos preguntamos sobre la existencia social de las siguientes opciones:

- Poder elegir entre casarse o vivir sola, con o sin hijos.

- Poder elegir entre tener hijos o no tenerlos.

- Poder elegir entre sostenerse materialmente por sí misma, o ser mantenida por un hombre.

La posibilidad de que una mujer viva sola no existe en el contexto analizado. Las únicas posibilidades de existencia social para las muijeres son permanecer en la casa de sus padres como hija de familia -aunque tenga hijos como madre soltera o esposa abandonada- o vivir conyugalmente con un hombre, solos o en casa de los padres o suegros. Si no existe un hombre que tenga vida sexual con ella, al menos ocasionalmente, y que contribuya al menos parcialmente a su sustento, la única posibilidad de vida socialmente aceptable para una mujer es regresar a la casa de sus padres.

Como se mencionó anteriormente, tampoco existe para las muijeres de este contexto la posibilidad de decidir vivir sin tener hijos. La existencia de una mujer sin hijos solamente fue imaginable como una anomalía no voluntaria. Las entrevistadas manifestaron sentimientos de gran compasión hacia las mujeres infértiles, y algunas imaginaron que la imposibilidad de tener hijos puede llevar a una mujer a perder la razón. Ninguna pudo imaginar que una mujer deseara no tener hijos. 
El trabajo femenino fue valorado positivamente por la mayor parte de estas mujeres. Casi todas tuvieron aspiraciones de estudio y trabajo antes de casarse, en especial las que lograron cierta escolaridad. Deseaban ser maestras, enfermeras o secretarias. Algunas trabajaron cuandoijovencitas, a veces empujadas por situaciones de precariedad doméstica, a veces porque fueron madres solteras, pero a veces también por un deseo de independencia, aprendizaje, sociabilidad y obtención de ingresos propios. Sin embargo, todas ellas dejaron de trabajar o de estudiar al casarse. Unas lo hicieron porque el esposo les prohibió trabajar. Otras, porque deseaban dejar de trabajar y que un hombre las mantuviera. Algunas de las mujeres más escolarizadas lo hicieron por sentir incompatible el cuidado de los hijos pequeños con el trabajo, y una de ellas aspiraba a volver a trabajar cuando crecieran un poco. Finalmente, una de las que deseaban ser mantenidas enviudó y su nueva pareja provee irregularmente, por lo que se ha visto obligada a trabajar sin desearlo.

En sus historias de vida, cerca de la mitad de las mujeres refirió que sus madres debieron hacerse cargo del sostenimiento del hogar, sea por abandono o fallecimiento del esposo, o por vivir situaciones de violencia y alcoholismo del cónyuge. Las características del hogar de origen condicionaron las opciones posteriores de estas mujeres, pues entre ellas se cuentan las que debieron unirse como consecuencia de un embarazo desde los 14 años y las que, a su vez, viven situaciones de violencia doméstica. Aunque algunas de estas mujeres admiraban la condición de trabajadora de su madre, consideraban que su trabajo fue condicionado por el fracaso en su vida matrimonial.

La investigación no contempló un estudio del mercado de trabajo femenino en la zona. Sin embargo, de las declaraciones de las entrevistadas se desprende que su opción de no trabajar no se vincula con limitaciones de ese mercado, sino con una percepción de incompatibilidad de su situación de mujeres casadas con el trabajo extrahogareño. El trabajo femenino parece ir contra la masculinidad del esposo, de los deberes maternales de la mujer y de la demostración social de logro matrimonial.

Estas percepciones indican que no existe la posibilidad de estilos de vida alternativos para las mujeres en este contexto, y esto limita sus posibilidades de opción sexual. Si la única forma de vida aceptable para una mujer es la conyugalidad y la dependencia económica, sus deseos, sentimientos y prácticas sexuales deben ajustarse a los cánones socialmente requeridos para lograr esa situación de mujer casada, 
con hijos tenidos en la unión, y sostenida por el esposo. Las posibilidades de opción sexual para las mujeres mexicanas de este contexto pasan por el control social del matrimonio y la procreación y por la división social del trabajo entre los sexos.

Valoración de la autonomía individual para tomar decisiones anticonceptivas

Las mujeres entrevistadas en el municipio de Actopan manifestaron diversas actitudes frente a la posibilidad que tienen las mujeres de tomar decisiones anticonceptivas.

Un primer grupo de mujeres no se sentía responsable de decidir sobre su vida reproductiva, atribuyendo a su esposo y al personal de salud todo el derecho a decidir sobre sus cuerpos y su capacidad procreativa. No expresaron disfrutar ni interesarse en su vida sexual, pero al mismo tiempo manifestaron absoluta disponibilidad para las demandas sexuales del esposo. Estas mujeres aparecen satisfechas con sus vidas, sin que parezcan necesitar mayor autonomía. Se trata de mujeres socializadas en un entorno rural aislado, que tuvieron muy poca escolaridad.

Un segundo grupo de mujeres expresó que sus aspiraciones y fantasías sobre el futuro se vieron truncadas por un inicio demasiado temprano, poco voluntario o poco satisfactorio de su vida reproductiva y conyugal. Tienen una mala relación con sus esposos y viven situaciones de violencia doméstica. Ninguna disfruta las relaciones sexuales, pero ceden a las presiones del esposo por no tener alternativa. La tensión entre su falta de deseos sexuales y las demandas del esposo genera conflictos. Expresan deseos de cierta autonomía, pero sienten que no pueden influir mucho sobre su realidad. La actitud desobligada o violenta de sus esposos justifica, para ellas, el que tomen decisiones anticonceptivas con independencia de su opinión. Se sienten vulnerables frente a los servicios de salud, pero manifiestan cierta indiferencia ante la posibilidad de presión o imposición médica. Se trata de mujeres con escasa escolaridad, pero con mayor experiencia urbana que las anteriores.

Un tercer grupo de opiniones correspondió a las mujeres de mayor escolaridad. Ellas tuvieron un periodo de noviazgo antes de la unión conyugal, y escogieron a sus esposos de acuerdo con sus atributos y por afecto. Tienen relaciones conyugales en las que están presen- 
tes los conflictos y desacuerdos, pero en las que hay afecto y colaboración de sus esposos, incluso respecto de las prácticas anticonceptivas. Algunas de estas mujeres dijeron que disfrutan o disfrutaron sus relaciones sexuales, y las otras manifestaron que discuten su falta de deseos con el esposo, sin que el conflicto se resuelva con violencia. Estas mujeres intentaron planear su descendencia, expresaron haber tenido algún margen de opciones en su vida y se responsabilizaron de sus decisiones. Sin embargo, entre ellas se cuentan quienesijustificaron la imposición de dispositivos anticonceptivos hacia mujeres que tienen "muchos" hijos. Su discurso coincide con el del personal de salud, pues expresan que el ideal es tener dos hijos para mantenerlos mejor, y que el médico debe decidirlo cuando la mujer no lo hace correctamente.

Finalmente, una de las mujeres en trevistadas expresó mucha asertividad en la toma de decisiones a lo largo de su vida, incluso en la adolescencia y en la elección del cónyuge, y fue quien manifestó con mayor fuerza la presencia de deseos personales, incluyendo deseos de tener hijos con independencia de la conyugalidad, y deseos eróticos. Ésta fue la única mujer que expresó un rechazo categórico a toda posibilidad de imposición sobre las decisiones de una mujer respecto de su cuerpo y su vida, tanto por parte del esposo, como de los servicios de salud o de extraños.

\section{Consideraciones finales}

Las normas prevalecientes en el contexto estudiado sobre el control de la sexualidad femenina corresponden a la visión religiosa que vincula la sexualidad de las mujeres con la procreación y que enajena el acceso de las mujeres a su propio cuerpo, negándoles la posibilidad de sentir deseos y placeres sensuales y de disfrutar de relaciones sexuales no procreativas. A estas normas corresponde una construcción cultural del género que asigna la conyugalidad como valor máximo del deber ser femenino y como única opción de vida legítima para las mujeres.

Esta zona rural se ha visto afectada por las situaciones de cambio social que ha experimentado el conjunto del país. Nos referimos a los cambios en los niveles de fecundidad, la escolaridad, la expansión de las formas urbanas de vida, del trabajo asalariado, de la participación femenina en la actividad económica remunerada, así como los cambios en la familia y las redes sociales. Estos cambios han producido transformaciones en las visiones del mundo y en los patrones repro- 
ductivos, pero parecen permear centralmente las visiones sobre el género y la sexualidad.

Entre las dimensiones que aparecen modernizadas en el contexto rural estudiado destaca el acceso de las mujeresijóvenes a la escolaridad, que les permite frecuentar varones fuera de su contexto familiar sin tener que establecer inevitablemente una relación conyugal con ellos. Esto les permite, en algunos casos, iniciar relaciones sexuales sin que necesariamente les siga un embarazo, y en otros, embarazarse sin que a la preñez siga una unión conyugal. La posibilidad de interactuar con varones les permite mayor acceso a elegir a su pareja, a admitir sus deseos y proyectos personales, y a veces, les permite dialogar respecto de ellos con su cónyuge.

Otra dimensión se refiere al acceso de las mujeres de este contexto a los servicios médicos de salud, hacia los que pueden canalizar sus necesidades de atención para la reproducción como alternativa a las formas más tradicionales de cuidado de los embarazos y alumbramientos. Las mujeres que acceden a cierta escolaridad adoptan una visión cercana a los servicios de salud en lo que se refiere a la reproducción humana: conocen la fisiología de la reproducción, hablan sobre deseo, placer y amor, y defienden la idea de limitar la procreación conyugal a dos hijos. Sin embargo, no cuestionan las normas locales sobre el inicio de la sexualidad femenina y la valoración única de lo femenino por medio de la conyugalidad y la maternidad.

En el contexto estudiado existe un acceso más o menos generalizado de las mujeres casadas y con hijos a la anticoncepción. Este acceso les permite tener la opción de evitar sufrimientos y riesgos derivados de la vida reproductiva, pero no parece permitirles aún un disfrute de las relaciones sexuales.

También aparecen modernizadas la intimidad y las relaciones de pareja. Mientras que las mujeres más rurales y menos escolarizadas no cuestionan la autoridad del esposo y de su familia y se adhieren de manera satisfactoria a una concepción ijerárquica del mundo en las que ellas ocupan una posición subordinada, pero protegida, otras mujeres viven solas con su esposo y sus hijos, a veces en relaciones de conflicto y vulnerabilidad, y otras en situaciones de mayor colaboración y afecto. Las mujeres más escolarizadas refieren la presencia de diálogo y negociación con sus esposos, y conceden importancia al amor y la atracción en la elección de pareja.

La presencia de diferentes posiciones de las mujeres respecto de las relaciones conyugales, de la autonomía en las decisiones sobre an- 
ticoncepción y reproducción, de la posibilidad de evitar relaciones sexuales que no desean, y de la posibilidad de experimentar deseos y placer erótico, indica que existe diversidad de respuestas individuales y de valoraciones sobre la reproducción, la sexualidad y las relaciones íntimas, aun en un contexto rural y marginado. Sin embargo, también indican el fuerte arraigo de ciertas construcciones sociales sobre la identidad de género y el control de la sexualidad femenina, que afectan el comportamiento hacia la anticoncepción. Se refieren a la conyugalidad y la maternidad legítima como únicas opciones de vida para las mujeres, y a la negación del derecho a una sexualidad no procreativa y placentera para ellas. La persistencia de estos valores expone a las mujeres a riesgos como las relaciones sexuales no deseadas, relaciones sexuales no protegidas -sobre todo antes de la unión conyugal y antes de tener hijos dentro de la unión-y embarazos no buscados.

Los valores culturales que rechazan una sexualidad placentera en las mujeres jóvenes pueden constituir dimensiones que dificultan el acceso a la anticoncepción en las etapas tempranas de la vida reproductiva y que subyacen en diversos problemas de salud reproductiva, tales como el embarazo no deseado, el aborto clandestino y la procreación temprana. La construcción social de la sexualidad es una de las relaciones entre la cultura, la fecundidad y la anticoncepción que requieren ser investigadas sistemáticamente en México desde perspectivas interdisciplinarias.

\section{Bibliografía}

Amuchástegui, A. (1994), "Culturas híbridas. El significado de la virginidad y la iniciación sexual para jóvenes mexicanos", reporte final de investigación, México, The Population Council.

Arias, P. (1991), "Dos nociones en torno al campo", trabajo presentado en el Seminario Mercados de Trabajo. Una Perspectiva Comparativa. Tendencias Generales y Cambios Recientes, México, Centro de Estudios Sociológicos, El Colegio de México, 24 al 25 de octubre.

Arias de Aramburó, R. (1995), "La sexualidad en las ciencias sociales", Reflexiones. Sexualidad, salud y reproducción, núm. 4, México, Programa Salud Reproductiva y Sociedad, El Colegio de México.

Bozon, M. y H. Leridon (1993), "Les constructions sociales de la sexualité", Sexualité et Sciences Sociales, Suplemento de Population, núm. 5, pp. 1174-1195.

Corona, Y. (1989), "Conceptualización y valoración del trabajo doméstico. El punto de vista de los niños" en Orlandina de Oliveira (coord.), Trabajo, 
poder y sexualidad, México, Programa Interdisciplinario de Estudios de la Mujer (PIEM), El Colegio de México, pp. 81-102.

Dixon-Müeller, R. (1993), "The Sexuality Connection in Reproductive Health", Studies in Family Planning, vol. 24, núm. 5, pp. 269-282.

Elu, Ma. del Carmen y L. Leñero (1992), De came y hueso. Estudios sociales sobre género y reproducción, México, Institu to Mexicano de Estudios Sociales (IMES).

Figueroa, Juan Guillermo (1994), "Elementos asociados a la valoración de la anticoncepción qurúrgica", reporte de investigación, México, Dirección General de Planificación Familiar, Secretaría de Salud.

- (coord.) (1995), La condición de la mujer en el espacio de la salud, México, El Colegio de México/Secretaría de Salud (en preparación).

García, Brígida (1988), Desarrollo económico y absorción de fuerza de trabajo en México, 1950-1980, México, El Colegio de México.

_ y Orlandina de Oliveira (1994), Trabajo femenino y vida familiar en México, México, El Colegio de México.

Kaztman, R. (1993), “¿Por qué los hombres son tan irresponsables?”, en Cambios en el perfil de las familias. La experiencia regional, Santiago de Chile, CEPAL, Pp. 110-121.

Liendro, E. (1993), "Sexualidad y trabajo en jóvenes varones de una colonia popular de la ciudad de México", proyecto de tesis de maestría en antropología, México, Escuela Nacional de Antropología e Historia (manuscrito).

Mellado, V., C. Zoila y X. Castañeda (1989), La atención al embarazo y el parto en el medio rural mexicano, México, Centro Interamericano de Estudios de Seguridad Social.

Mummert, G. (1986), "Mujeres de migrantes y mujeres migrantes de Michoacán: nuevos papeles para las que se quedan y las que se van", en G. López Castro y Th. Calvo (eds.), Movimientos de población en el occidente de México, México, El Çolegio de Michoacán/Centre D’Études Mexicaines et Centraméricaines, pp. 87-104.

Oliveira, Orlandina de (1984), "Migración femenina, organización familiar y mercados laborales en México", Comercio Exterior, vol. 34, núm. 7, pp. 676687.

Poder Ejecutivo Federal (1995), Programa Nacional de Población 1995-2000, México.

Rocha, M. (1995), "Historia de los comportamientos amorosos y su transformación. El noviazgo 1935-1968", en Reflexiones. Sexualidad, salud y reproducción, núm. 4, México, Programa Salud Reproductiva y Sociedad, El Colegio de México, pp. 27-28.

Rosado, G. (1990), "De campesinas inmigrantes a obreras de la fresa en el valle de Zamora, Michoacán" en G. Mummert (ed.), Población y trabajo en contextos regionales, Zamora, El Colegio de Michoacán.

Salas, M. (1995), “Lactancia materna y trabajo asalariado: ¿irreconciliables?”, en S. González (ed.), Las mujeres y la salud, México, El Colegio de México, pp. 93-126. 
Salles, V. (1995), "Familia y sexualidad", en Reflexiones. Sexualidad, salud y reproducción, núm. 4, México, Programa Salud Reproductiva y Sociedad, El Colegio de México.

Szasz, I (1995), "La migración femenina y los mercados de trabajo en México", México, El Colegio de México (mimeo.).

Tuirán, R. (1993), "Estrategias familiares de vida en época de crisis: el caso de México", Cambios en el perfil de las familias: la experiencia regional, Santiago de Chile, CEPAL, pp. 319-354.

Villaseñor, M. y N. Alfaro (1995), "Factores socioculturales que intervienen en la determinación del deseo o no deseo del embarazo en la adolescente", trabajo presentado en el Taller sobre Sexualidad y Reproducción, México, Instituto Nacional de Perinatología, 29 al 31 de marzo.

Weeks, J. (1995), "Sexual Values in the Age of Alds", conferencia presentada en el Curso de Especialización sobre Perspectivas de Ciencias Sociales en Salud Reproductiva, México, El Colegio de México, enero.

Zavala de C., M. E. (1988), Cambios de la fecundidad en México, México, Secretaría de Salud. 